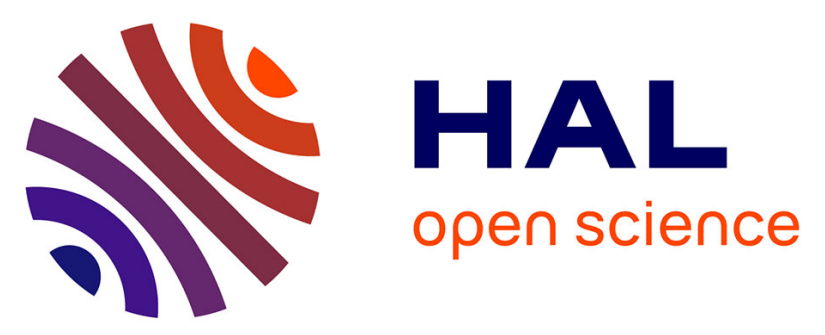

\title{
A Reversible Electron Relay to Exclude Sacrificial Electron Donors in the Photocatalytic Oxygen Atom Transfer Reaction with $\mathrm{O} 2$ in Water
}

Nhat Tam Vo, Yasmina Mekmouche, Thierry Tron, Régis Guillot, Frédéric

Banse, Zakaria Halime, Marie Sircoglou, Winfried Leibl, Ally Aukauloo

\section{To cite this version:}

Nhat Tam Vo, Yasmina Mekmouche, Thierry Tron, Régis Guillot, Frédéric Banse, et al.. A Reversible Electron Relay to Exclude Sacrificial Electron Donors in the Photocatalytic Oxygen Atom Transfer Reaction with O2 in Water. Angewandte Chemie International Edition, 2019, 10.1002/anie.201907337. hal-02301619

\section{HAL Id: hal-02301619 https://hal.science/hal-02301619}

Submitted on 10 Nov 2020

HAL is a multi-disciplinary open access archive for the deposit and dissemination of scientific research documents, whether they are published or not. The documents may come from teaching and research institutions in France or abroad, or from public or private research centers.
L'archive ouverte pluridisciplinaire HAL, est destinée au dépôt et à la diffusion de documents scientifiques de niveau recherche, publiés ou non, émanant des établissements d'enseignement et de recherche français ou étrangers, des laboratoires publics ou privés. 


\title{
Reversible Electron Relay to Exclude Sacrificial Electron Donor in Photocatalytic Oxygen Atom Transfer Reaction with $\mathrm{O}_{2}$ in Water
}

\author{
Nhat Tam Vo, ${ }^{a}$ Yasmina Mekmouche, ${ }^{b}$ Thierry Tron, ${ }^{b}$ Régis Guillot, ${ }^{a}$ Frédéric Banse, ${ }^{a}$ Zakaria Halime, ${ }^{a}$ \\ Marie Sircoglou, ${ }^{a}$ Winfried Leibl, ${ }^{{ }^{c} \mathrm{c}}$ and Ally Aukauloo ${ }^{*} \mathrm{a}, \mathrm{c}$
}

Dedicated to Shunichi Fukuzumi

\begin{abstract}
Using light energy and $\mathrm{O}_{2}$ for the direct chemical oxidation of organic substrates is a major challenge in the development of clean and sustainable processes. A stubborn limitation in this strategy resides in the use of sacrificial electron donors to activate $\mathrm{O}_{2}$ through a reductive quenching process of the photosensitizer thereby generating undesirable side products. We found that a reversible electron acceptor, methyl-viologen, can act as electron shuttle to oxidatively quench the photosensitizer, $\left[R u(b p y)_{3}\right]^{2+}$, generating the highly oxidized chromophore and the powerful reductant methyl-viologen radical $\mathrm{MV}^{+}$. $\mathrm{MV}^{*}$ can then reduce an iron(III) catalyst to the iron(II) form and concomitantly $\mathrm{O}_{2}$ to $\mathrm{O}_{2}{ }^{*}$ in an aqueous medium to generate an active iron(III)-(hydro)peroxo species. The oxidized photosensitizer is reset to its ground state by oxidizing an alkene substrate to an alkenyl radical cation. Closing the loop, the reaction of the iron reactive intermediate with the substrate or its radical cation leads to the formation of two oxygenated compounds, the diol and the aldehyde following two different pathways. Our report provides a new paradigm to perform photocatalytic oxidation of organic substrates with solely light as energy input and $\mathrm{O}_{2}$ as oxygen atom source.
\end{abstract}

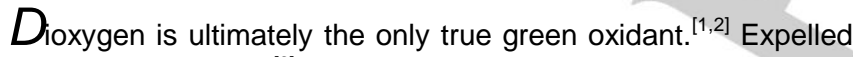
from photosynthesis ${ }^{[3]}$ it constitutes a crucial molecular brick for the energy supply chain in biology. It also serves as the main supplier of O-atoms in the biosyntheses of essential organic molecules. $^{[4,5]}$ Although the thermodynamics behind these chemical reactions are favorable, kinetic limitations come from the fundamental paramagnetic state of $\mathrm{O}_{2}$. This limitation can be lifted off when $\mathrm{O}_{2}$ is partnered with paramagnetic species or excited triplet states that can undergo single electron transfer reactions. ${ }^{[6-9]}$ Chemists have taken inspiration from biology to develop metal complexes that can bind and activate dioxygen in

[a] N. T. Vo, Dr. Régis Guillot, Prof. F. Banse, Dr. Z. Halime, Dr. M. Sircoglou, Prof. A. Aukauloo,

ICMMO, Université Paris Sud, Université Paris Saclay, CNRS F-91405 Orsay Cedex, France. E-mail: ally.aukauloo@u-psud.fr

[b] Dr. Y. Mekmouche, Dr. Thierry Tron

Aix Marseille Université, Centrale Marseille, CNRS, ISM2 UMR 7313, 13397, Marseille, France

[c] Dr. W. Leibl, Prof. A. Aukauloo,

Institute for integrative Biology of the Cell (I2BC), CEA, CNRS

Université Paris-Saclay, UMR 9198

F-91191, Gif-sur-Yvette, France.

E-mail: winfried.leibl@cea.fr

Supporting information for this article is given via a link at the end of the document. presence of co-reductants. ${ }^{[10-13]}$ Photoactivating $\mathrm{O}_{2}$ at a metal complex through light-induced electron transfer is an even more desirable target. ${ }^{[14-16]}$ However, this quest is dramatically challenging and has lagged behind the great boom we have witnessed during the last decade in the field photocatalysis. In fact $\mathrm{O}_{2}$ is considered as an external deleterious impurity in the vast majority of the reported photo-chemical transformations. ${ }^{[17]}$ This classical approach also suffers from the necessity of sacrificial electron donors (SED) to activate $\mathrm{O}_{2}$ for oxygen atom transfer (OAT) reactions thereby limiting the preparative scope.$^{[18,19]}$ Nocera and coworkers have developed face to face bis-iron(III)- $\mu$-oxo porphyrin where they have shown that upon visible light irradiation dioxygen acts both as the final oxidant and the oxygen atom donor in the oxidation of alkenes albeit in benzene. ${ }^{[20]}$ While, Fukuzumi and coll. took profit of the high energy long-lived charge separated state of 9-mesityl-10methylacridinium ion to generate $\mathrm{O}_{2}{ }^{-}$and an alkenyl radical cation that couple to give an unstable dioxetane derivative that cleaves into ketones as only products. ${ }^{[1,22]}$

Henceforth, much effort is still needed in the quest towards using light and $\mathrm{O}_{2}$ without sacrificial electron donor to manage and enlarge the reactivity of reduced oxygen species under mild conditions. In this study we interrogate a counter intuitive approach for the light-driven reductive activation of $\mathrm{O}_{2}$ by using a reversible electron acceptor to preclude the use of sacrificial electron donor. We found that the introduction of methylviologen dication $\left(\mathrm{MV}^{2+}\right)$ in a mixture of the $\left[\mathrm{Ru}(\mathrm{bpy})_{3}\right]^{2+}$, abbreviated as $\left(\left[\mathrm{Ru}^{\mathrm{II}}\right]\right)$, photosensitizer and a semi-hemic iron(III) catalyst allows aerobic oxidation of alkene substrate in aqueous medium. We show that the oxidative quenching of the photosensitizer generates the highly oxidized chromophore and the powerful reductant methyl-viologen radical $\mathrm{MV}^{+\cdot}$ that can then concomitantly reduce the iron(III) complex to the iron(II) form and $\mathrm{O}_{2}$ to $\mathrm{O}_{2}{ }^{*-}$. Further reaction between the iron(II) complex and $\mathrm{O}_{2}{ }^{*-}$ generates an active iron(III)-peroxo species. ${ }^{[10,23,24]}$ The oxidized photosensitizer is reset to its ground state by oxidizing an alkene substrate to an alkenyl radical cation. Closing the loop, the reaction of the active iron complex and the organic radical or the alkene lead to the formation of two oxygenated compounds, the aldehyde and the diol respectively. Isotopic labelling experiments support that $\mathrm{O}_{2}$ is at the origin of the inserted oxygen atoms.

For this study, we prepared an iron complex with the DPPy (DipyrrinDiPyridine) ligand we previously designed in our lab (Fig. 1 left). ${ }^{[25]}$ Metalation of the DPPy ligand with $\mathrm{Fe}(\mathrm{OTf})_{2}$ led to the formation of the iron(II) precursor complex that upon exposure to air yielded the $\left\{\left[(\mathrm{DPPy})(\mathrm{EtOH}) \mathrm{Fe}^{\mathrm{III}}\right]_{2} \mathrm{O}\right\}(\mathrm{OTf})_{2}$, a $\mu$ - 
oxo iron(III) dimer shorthanded as $\mathrm{I}(\mathrm{OTf})_{2}$ (see $\mathrm{SI}$ ). The underlying reactivity is reminiscent of that of the corresponding iron(II) porphyrin (Por) derivatives where $\mathrm{O}_{2}$ binding and subsequent $\mathrm{O}-\mathrm{O}$ bond cleavage leads to the highly oxidized iron(IV)-oxo species that ultimately reacts with the starting iron(II) complex to generate the $\left[(\text { Por }) \mathrm{Fe}^{\text {III }}\right]_{2} \mathrm{O}$ derivative. ${ }^{[26]}$ An ORTEP view of $\mathbf{I}$ is given in Figure 1. The coordination sphere of each iron(III) ion is described by the four nitrogen atoms of the DPPy ligand in a meridional plane and oxygen atoms from the bridging oxo and one ethanol molecule in apical positions. Two triflate counter anions assure electroneutrality. Given the hemiporphyrinic nature of the DPPy ligand, we observed two Fe$\mathrm{N}$ bond lengths (av. $2.05 \AA$ ) within the same range as those for a typical iron(III) porphyrin and two longer Fe-N bonds (av. 2.21 A) with the pyridine groups (see Table SI1 \& SI2 for all the metric parameters)
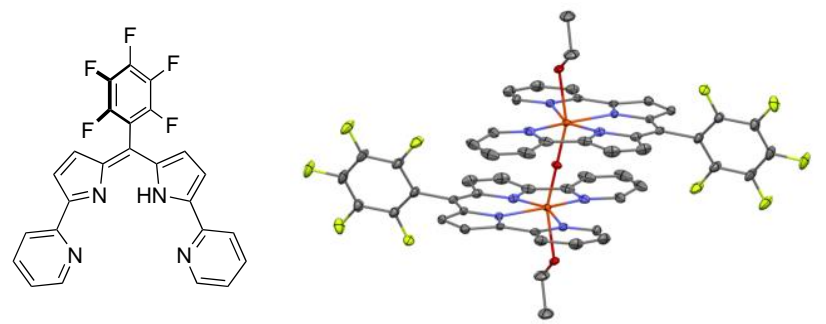

Figure 1: Molecular drawing of DPPyH proligand and ORTEP view of the X-ray crystallographic structure of $\left\{\left[(\mathrm{DPPy})(\mathrm{EtOH}) \mathrm{Fe}^{\mathrm{III}}\right]_{2} \mathrm{O}\right\}^{2+}(\mathrm{I})$. The hydrogen atoms have been omitted for clarity.

$\mathbf{I}(\mathrm{OTf})_{2}$ was engaged in a $\mathrm{B} \& \mathrm{R}$ buffer $(\mathrm{pH} 4)$ aqueous mixture with the $\left[\mathrm{Ru}^{\mathrm{II}}\right]$ photosensitizer and an excess of a water-soluble alkene, sodium styrene-4-sulfonate (hereby shorthanded as S). Upon continuous illumination using white light (LED lamp equipped with a Wratten $2 \mathrm{E}$ filter, $\lambda>415 \mathrm{~nm}$ ) and under an aerobic atmosphere no oxidation product was detected. In a subsequent experiment, $\mathrm{MV}^{2+}$ was added to the previous mixture followed by irradiation in air. Remarkably, in presence of $\mathrm{MV}^{2+}$, two oxygenated products were detected, the diol and the benzaldehyde derivatives (Table SI3, Fig. SI5), with an overall TON of ca. 80 (Scheme 1).

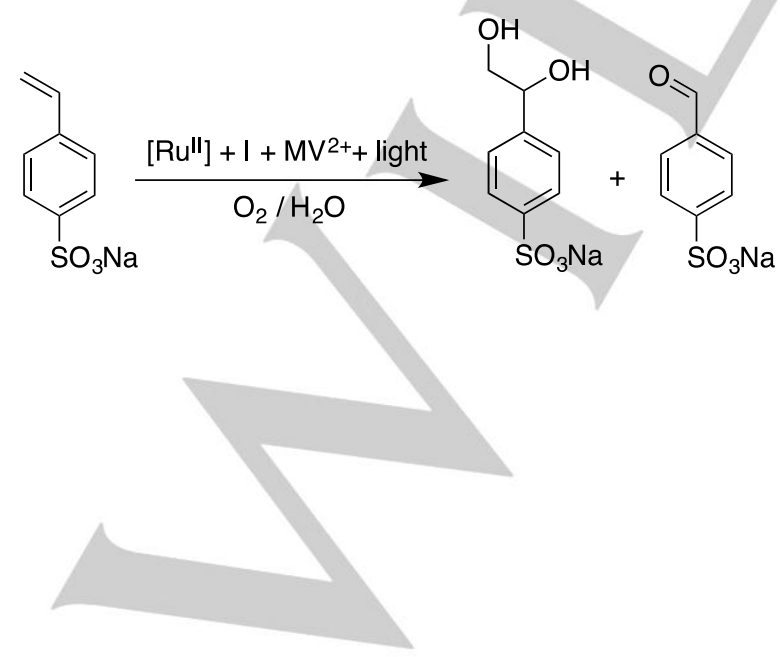

Scheme 1: Photocatalytic oxygen atom transfer reaction of styrene sulfonate with $\mathrm{O}_{2}$ in absence of sacrificial electron donor.

This value falls roughly within the range observed for highly oxidized iron species generated upon reaction of iron complex models with $\mathrm{O}_{2}$ in presence of electron and proton donors. ${ }^{[27,13,28]}$ Isotopic labelling experiments using ${ }^{18} \mathrm{O}_{2}$ were carried out to determine the origin of the oxygen atom(s) inserted in the products. The HPLC-HRMS analysis of the corresponding photocatalytic experiments indeed confirmed that the oxygen atoms stem from ${ }^{18} \mathrm{O}_{2}$ (Fig. SI13).

Such an intriguing scenario, where the only presence of a reversible electron acceptor ousts the SED for the reductive activation of $\mathrm{O}_{2}$, provided us with a strong incentive to delineate the photocatalytic reaction scheme. A series of control experiments combined with the detection of relevant intermediate species by Laser Flash Photolysis allowed us to propose a plausible photocatalytic mechanism for the oxygenation reaction. In a first blank experiment, we excluded both the $\mu$-oxo Fe $\mathrm{F}^{\mathrm{III}}$ dimer $(\mathbf{I})$ and the $\mathrm{MV}^{2+}$ (see Table SI3, Fig. SI5). No traces of oxygenated products were detected under such experimental conditions, allowing us to expedite the singlet $\mathrm{O}_{2}$ pathway that could interfere in the oxidation of the organic substrate. Of note, this experimental configuration also sets aside any organic radical formation that could trigger autooxidation reaction with $\mathrm{O}_{2}{ }^{[29]}$ Furthermore, no photodegradation of the photosensitizer was observed under our irradiation conditions (Fig. SI3) ruling out the participation of chemically altered intermediate such as $\left[\mathrm{Ru}(\mathrm{bpyy})_{2}\left(\mathrm{H}_{2} \mathrm{O}\right)_{2}\right]^{2+}$ as potent photooxidation catalyst. ${ }^{[30]}$

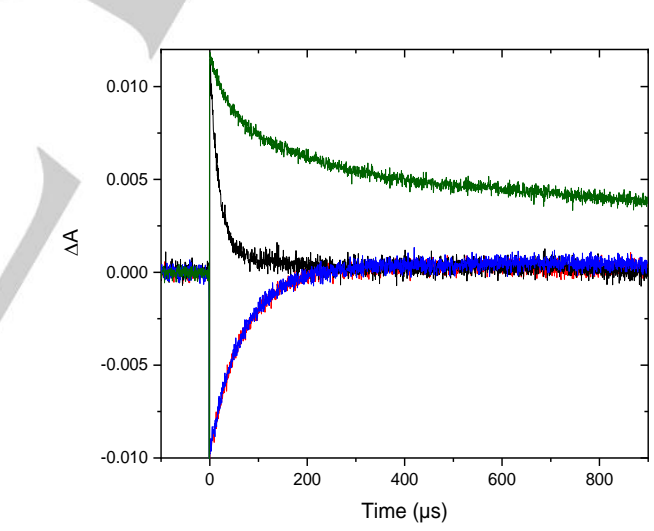

Figure 2: Time resolved absorption changes of a $\mathrm{B} \& \mathrm{R}(\mathrm{pH} 4)$ buffer solution of $\left[\mathrm{Ru}(\mathrm{bpy})_{3}\right]_{\mathrm{Cl}}(30 \mu \mathrm{M})$ and $\mathrm{MV}^{2+}(4 \mathrm{mM})$ in presence of sodium 4styrenesulfonate (100 mM) at $605 \mathrm{~nm}$ (green) and $450 \mathrm{~nm}$ (blue) under argon; at $605 \mathrm{~nm}$ (black) and $450 \mathrm{~nm}$ (red) in aerobic conditions. 
In a subsequent experiment, where a mixture of [Ru"], $\mathrm{S}$ and $\mathrm{O}_{2}$ was irradiated in presence of $\mathrm{MV}^{2+}$, only trace amounts of oxidized substrate were detected, bringing unambiguous support that the presence of the iron complex is essential for the observed photocatalytic reaction. The photoexcitation with a laser pulse at $460 \mathrm{~nm}$ of an aqueous mixture of [Rull] and $\mathrm{MV}^{2+}$ in presence and absence of $\mathrm{O}_{2}$ resulted in both cases in the formation of $\mathrm{MV}^{+\cdot}$ detected by its characteristic absorption

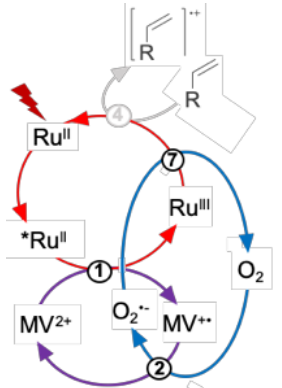

maximum around $605 \mathrm{~nm}$, and [Ru $\left.{ }^{\mathrm{II}}\right]$ probed by the bleaching of the MLCT band at $450 \mathrm{~nm}$ (Fig. SI7). However, the faster decay of the $\mathrm{MV}^{+\cdot}$ radical compared to the $\left[\mathrm{Ru}^{\mathrm{III}}\right]$ species in the presence of $\mathrm{O}_{2}$, clearly supports a rapid electron transfer from $\mathrm{MV}^{+\bullet}$ to $\mathrm{O}_{2}$ (Fig. SI8). ${ }^{[31,32]}$ Back electron transfer to [Ru'l'] occurs in a second order reaction regenerating the $\left[R u^{\prime \prime}\right]$ state quantitatively with similar kinetics as back electron transfer from $\mathrm{MV}^{+\cdot}$ in the absence of $\mathrm{O}_{2}$. Interestingly, in a deaerated solution and in presence of the olefin, we found that the recovery of the $\left[R u^{\prime l}\right]$ is faster than the lifetime of $\mathrm{MV}^{+\bullet}$ (Fig. 2 \& Fig. SI9). This observation can be assigned to the oxidation of the alkene by $\left[R u^{\prime \prime \prime}\right]$ through an intermolecular electron transfer process to form an alkenyl radical cation (step 4). ${ }^{[33]}$ The chemical oxidation of the alkene by $\left[\mathrm{Ru}^{\mathrm{III}}\right]$ complex was performed and confirmed by the EPR detection of an organic radical (Fig. SI6) which brings further support for this reaction pathway. The trace amount of oxidized substrate $(<1 \%$ of aldehyde) observed under these conditions i.e. in the absence of I may thus originate from a minor side reaction of the singly oxidized olefin derivative with $\mathrm{O}_{2} \cdot{ }^{[34]}$ In Scheme 2, we recapitulate the photophysical events in the absence of complex I. In this experimental set, the lack of the iron complex leads to the rapid annihilation of the charge separation state by recombination of the superoxide radical with

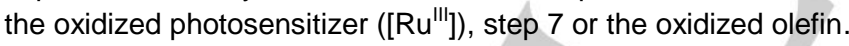
Scheme 2: Predominating photophyscial events: steps 1, 2 and 7 in the text, and minor event step 4 upon irradiation of a mixture of the photosensitizer / methylviologen / substrate / $\mathrm{O}_{2}$.
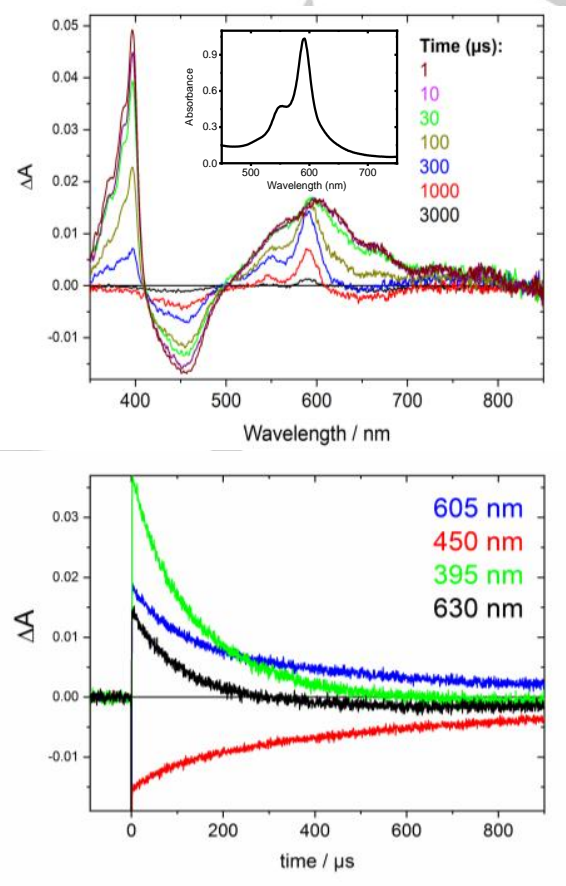

We then assessed the role of complex I. In a first control experiment where we omitted $\mathrm{MV}^{2+}$ but introduced complex I, no oxidized substrate was detected. This result indicates that no charge shift process is undergoing from the excited state of the photosensitizer to complex I in agreement with the absence of quenching of the emission life time of *[Ru"] upon addition of I (Fig. Sl10).

Figure 3: Top: Transient absorption spectra from an Ar-saturated B\&R buffer solution of $\left[\mathrm{Ru}(\mathrm{bpy})_{3}\right]^{2+}(30 \mu \mathrm{M}), \mathrm{MV}^{2+}(4 \mathrm{mM})$ and I $(30 \mu \mathrm{M})$ at the indicated delay times after excitation and (inset) UV-visible spectrum of (DPPy)Fe" in water under argon. Bottom: Time resolved absorption changes at $390 \mathrm{~nm}$ (green), $450 \mathrm{~nm}$ (red), $605 \mathrm{~nm}$ (blue) and $630 \mathrm{~nm}$ (black) corresponding to the contribution of $\mathrm{MV}^{+}$, [Rull, both $\mathrm{MV}^{+\cdot}$ and $\mathrm{Fe}$ (II) complex, mainly $\mathrm{Fe}$ (III) respectively.

Furthermore, the absence of any oxidized products corroborates the lack of photocatalytic activity of the $\left\{\left[(\mathrm{DPPy}) \mathrm{Fe}^{\text {III }}\right)_{2} \mathrm{O}\right\}^{2+}$ compound $(\mathbf{I})$ in aqueous medium. ${ }^{[35]}$ We then interrogated the role of $\mathbf{I}$ in presence of $\mathrm{MV}^{2+}$. Under an inert atmosphere, the oxidative quenching of the photosensitizer and the formation of $\mathrm{MV}^{+\cdot}$ again prevailed. However, a rapid fading of the absorption features of the $\mathrm{MV}^{+}$radical is observed that matched with the formation of the reduced (DPPy)Fe", detected by two absorption bands in the visible region at around 550 and $590 \mathrm{~nm}$ (Fig. 3) while the feeble broad bleaching band around $650 \mathrm{~nm}$ detected at $1 \mathrm{~ms}$ can be attributed to the disappearance of the $\mathrm{Fe}$ (III) complex I. The recovery of $\left[R u^{\prime \prime}\right]$ is quite slow under these conditions and can reasonably be attributed to recombination with $\mathrm{Fe}$ (II) (compare blue and red traces in Fig. 3, bottom) to form $\mathrm{Fe}$ (III) (black trace). In presence of $\mathrm{O}_{2}$, the electronic absorption signature of the (DPPy)Fe" can still be detected (Fig. $\mathrm{SI12}$ ) albeit with lower intensity than in the absence of $\mathrm{O}_{2}$. The lower yield in presence of $\mathrm{O}_{2}$ is compatible with the competitive reduction of $\mathrm{I}$ vs. $\mathrm{O}_{2}$ by $\mathrm{MV}^{+\cdot}$ to generate the (DPPy) Fe" and $\mathrm{O}_{2}{ }^{\circ}$ species respectively with a branching ratio determined essentially by the relative concentrations of $\mathrm{I}$ and $\mathrm{O}_{2}$. Scheme 3 illustrates the different events occurring after excitation of the photosensitizer leading to the formation of the two main oxidized products i.e., the diol and benzaldehyde. Importantly, our global photocatalytic cycle is in sharp contrast with the classical photoactivation scheme, inasmuch as there is no intervention of a SED. Traditionally, the function of the SED serves to aliment the photocatalytic process with electrons for the activation of $\mathrm{O}_{2} \cdot{ }^{[36]}$ As depicted in Scheme 2, the first photoinduced sequence relies on the oxidative quenching of the photosensitizer to form the highly oxidizing $\left[\mathrm{Ru}^{\mathrm{III}}\right]$ and the powerful reductant $\mathrm{MV}^{+\bullet}$ (step 1). Laser Flash Photolysis experiments supported by the redox properties of each partner $\left(\mathrm{E}^{\circ}\left(\mathrm{MV}^{2+} / \mathrm{MV}^{+*}\right)=-0.69 \mathrm{~V} ;{ }^{[37]}\right.$ $\mathrm{E}^{\circ}\left(\mathrm{O}_{2} / \mathrm{O}_{2}{ }^{\circ-}\right)=-0.40 \mathrm{~V}$ vs. SCE; ${ }^{[38]} \mathrm{E}^{\circ}\left(\mathrm{Fe}^{\mathrm{III}} \mathrm{Fe} \mathrm{e}^{\mathrm{III}} / \mathrm{Fe} \mathrm{e}^{\mathrm{III}} \mathrm{Fe} \mathrm{e}^{\mathrm{\prime l}}\right)=0.23 \mathrm{~V}$

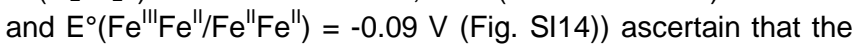
$\mathrm{MV}^{+\cdot}$ radical can reduce both the iron(III) complex and $\mathrm{O}_{2}$ (steps 2 and 2 ' in Scheme 3). 
Scheme 3: Proposed mechanism of the photocatalytic oxidation of sodium styrene-4-sulfonate by the photosensitizer / iron catalyst / methylviologen mixture to form the diol and aldehyde products.

The resulting iron(II) complex and $\mathrm{O}_{2}{ }^{*-}$ species ultimately combine to form an iron(III)-peroxo type intermediate (step 3). Note that at $\mathrm{pH} \mathrm{4}$, the superoxide radical anion is most likely to be protonated to produce a hydroperoxyl radical $\left(\mathrm{pKa}\left({ }^{\circ} \mathrm{OOH} /\right.\right.$ $\left.\left.\mathrm{O}_{2}{ }^{--}\right)=4.7\right)^{[38,39]}$ that reacts with $\mathrm{Fe}(\mathrm{II})$ to produce $\mathrm{Fe}(\mathrm{III})-\mathrm{OOH} .^{[40]}$ All attempts to trap the iron(III)-(hydro)peroxo intermediate in aqueous medium from the reaction of a chemically prepared (DPPy)Fe" and superoxide anion were unfruitful. However, such intermediates have been caught with other iron complexes, spectroscopically characterized and their reactivity modes were demonstrated in organic medium. ${ }^{[41,42]}$ Turning our attention to the oxidant issued from the first photophysical event; the $\left[\mathrm{Ru}^{\mathrm{III}}\right]$ species can oxidize the alkene to form an alkenyl radical cation thereby recycling the photosensitizer to its resting state (step 4). The formed organic radical species leads to one of the two main photoproducts that we evidenced, namely the benzaldehyde sulfonate. As already elucidated from previous studies, this product can derive from the formation of an unstable dioxetane species where $\mathrm{O}-\mathrm{O}$ and $\mathrm{C}-\mathrm{C}$ bonds cleavage delivers the benzaldehyde derivative. The direct reaction of the superoxide radical anion with the singly oxidized alkenyl radical cation to form the dioxetane intermediate can be ruled out under our experimental conditions. Indeed, as already mentioned, the blank experiment where a mixture of $\left[\mathrm{Ru}^{\prime \prime}\right],\left[\mathrm{MV}^{2+}\right], \mathrm{S}$ and $\mathrm{O}_{2}$ was irradiated only lead to a minute amount of oxidized photoproduct. Henceforth, we can arguably propose that the formation of the dioxetane results from the reaction of the alkenyl radical cation, formed by the electron transfer from the alkene to the oxidized $\left[R u^{\prime \prime \prime}\right]$ (step 4), with the Fe'III-peroxo intermediate (step 5). The other characterized photoproduct was the diol derivative (step 6) Its formation emanates from the $\mathrm{Fe}^{\mathrm{III}}\left(\eta^{2}-\mathrm{OOH}\right)$ species which, in turn, can evolve via heterolytic $\mathrm{O}-\mathrm{O}$ cleavage to form an $\mathrm{Fe}^{\mathrm{V}}(\mathrm{O})(\mathrm{OH}) .{ }^{[43-45]}$ This intermediate can concertedly fix two oxygen atoms to the alkene to yield the cis-diol product. ${ }^{18} \mathrm{O}$ isotopic labelling experiments were undertaken to interrogate the origin and the pattern of the inserted oxygen atoms. When the photocatalytic run was realized in presence of a mixture of ${ }^{18} \mathrm{O}_{2}$ and ${ }^{16} \mathrm{O}_{2}$, the cis-diol with two inserted ${ }^{18} \mathrm{O}$ atoms was detected in the HRMS together with the ${ }^{18} \mathrm{O}^{16} \mathrm{O}$ and ${ }^{16} \mathrm{O}^{16} \mathrm{O}$ labelled diol products. This experimental finding clearly supports that $\mathrm{O}_{2}$ is the actual source of oxygen atoms. The presence of mixed oxygen-labelled diol derivative can be rationalized through dynamic water exchange between an iron-bound hydroxo ligand and bulk water. ${ }^{[46-48]}$ Alternatively the formation of the diol may come from the ring opening of an epoxide formed from the high valent $\mathrm{Fe}$-oxo intermediate. When the photocatalytic run was realized at $\mathrm{pH} 6$, only the epoxide and the aldehyde were revealed (Table SI3, Fig. SI5). This subtle reactivity control brings further confirmation that the oxygen atom transfer reactions are guided through activated forms of $\mathrm{O}_{2}$ at the metal center. These mechanistic aspects have been developed in literature and are recalled in the SI (Scheme. Sl1). Further control experiment where complex I was substituted by an iron(III) salt $\left(\mathrm{FeCl}_{3}\right)$ revealed only a trace of aldehyde exempting the reactivity through a radical process (Fig. SI5).

The study we present here provides a new paradigm to perform photoinduced oxygen atom transfer reactions with solely light and $\mathrm{O}_{2}$ in aqueous solution, without the "evil necessity" of a sacrificial electron donor. An introspection of the photocatalytic

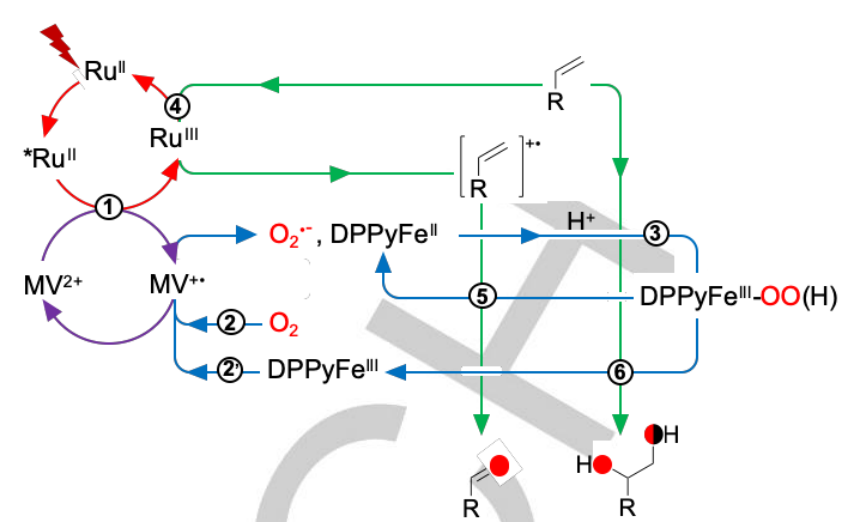

cycle points to the crucial role of the reversible charge carrier to produce $\mathrm{O}_{2}{ }^{\circ-}$ and reduce an iron(III) complex to form the activated $\mathrm{Fe}^{\text {III-}}$-(hydro)peroxo as the archetypal OAT reactive species. Meanwhile, the oxidized photosensitizer is reset to its resting state through oxidation of the olefin substrate to produce an alkenyl radical cation. The latter and the olefin can react with the active catalytic species to form oxygenated products. The quantum yield for formation of the oxidized products is estimated to about $2.5 \%$ (see $\mathrm{SI}$ ). Work is now in progress to interrogate the limiting steps in the light-induced electron transfer processes.

\section{Acknowledgements}

This work was supported by the ANR Multiplet (ANR-15-CE070021-01), LABEX CHARMMMAT (ANR-11-LABX-0039), and the French Infrastructure for integrated Structural Biology (FRISBI) ANR-10-INSB-05-01.

Keywords: oxygen atom transfer $\cdot$ photocatalysis $\cdot$ timeresolved spectroscopy $\bullet$ iron complexes $\bullet$ electron relay

C.-J. Li, P. T. Anastas, Chem. Soc. Rev. 2012, 41, 1413-1414.

R. A. Sheldon, I. W. C. E. Arends, U. Hanefeld, Appl. Organomet Chem. 2007, 21, 1002-1002.

J. Barber, Philos. Trans. R. Soc. Math. Phys. Eng. Sci. 2007, 365,

1007-1023.
Y.-F. Liang, N. Jiao, Acc. Chem. Res. 2017, 50, 1640-1653.

[4] Y.-F. Liang, N. Jiao, Acc. Chem. Res. 2017, 50, 1640-1653.
[5] S. S. Stahl, Angew. Chem. Int. Ed. 2004, 43, 3400-3420.

[6] T. Punniyamurthy, S. Velusamy, J. lqbal, Chem. Rev. 2005, 105 2329-2364.

[7] Z. Shi, C. Zhang, C. Tang, N. Jiao, Chem. Soc. Rev. 2012, 41, 33813430 .

[8] L. Boisvert, K. I. Goldberg, Acc. Chem. Res. 2012, 45, 899-910.

[9] J. Piera, J.-E. Bäckvall, Angew. Chem. Int. Ed. 2008, 47, 3506-3523.

[10] S. Sahu, D. P. Goldberg, J. Am. Chem. Soc. 2016, 138, 11410-11428.

[11] M. Martinho, G. Blain, F. Banse, Dalton Trans 2010, 39, 1630-1634.

[12] A. Thibon, J. England, M. Martinho, V. G. Young, J. R. Frisch, R Guillot, J.-J. Girerd, E. Münck, L. Que, F. Banse, Angew. Chem. Int Ed. 2008, 47, 7064-7067.

[13] H. Maid, P. Böhm, S. M. Huber, W. Bauer, W. Hummel, N. Jux, H. Gröger, Angew. Chem. Int. Ed. 2011, 50, 2397-2400.

[14] A. Maldotti, C. Bartocci, R. Amadelli, E. Polo, P. Battioni, D. Mansuy, J. Chem. Soc. Chem. Commun. 1991, 0, 1487-1489.

[15] J. Rosenthal, T. D. Luckett, J. M. Hodgkiss, D. G. Nocera, J. Am Chem. Soc. 2006, 128, 6546-6547.

[16] B. Mühldorf, R. Wolf, Angew. Chem. Int. Ed. 2016, 55, 427-430.

[17] L. Buzzetti, G. E. M. Crisenza, P. Melchiorre, Angew. Chem. Int. Ed. 2019, 58, 3730-3747.

[18] W. Iali, P.-H. Lanoe, S. Torelli, D. Jouvenot, F. Loiseau, C. Lebrun, O Hamelin, S. Ménage, Angew. Chem. Int. Ed. 2015, 54, 8415-8419.

[19] F. Avenier, C. Herrero, W. Leibl, A. Desbois, R. Guillot, J.-P. Mahy, A Aukauloo, Angew. Chem. Int. Ed. 2013, 52, 3634-3637.

[20] J. Rosenthal, B. J. Pistorio, L. L. Chng, D. G. Nocera, J. Org. Chem 2005, 70, 1885-1888.

[21] H. Kotani, K. Ohkubo, S. Fukuzumi, J. Am. Chem. Soc. 2004, 126, 15999-16006.

[22] K. Ohkubo, T. Nanjo, S. Fukuzumi, Org. Lett. 2005, 7, 4265-4268. 
[23] E. McCandlish, A. R. Miksztal, M. Nappa, A. Q. Sprenger, J. S. Valentine, J. D. Stong, T. G. Spiro, J. Am. Chem. Soc. 1980, 102, 4268-4271.

[24] F. Li, K. M. Van Heuvelen, K. K. Meier, E. Münck, L. Que, J. Am. Chem. Soc. 2013, 135, 10198-10201.

[25] C. Ducloiset, P. Jouin, E. Paredes, R. Guillot, M. Sircoglou, M. Orio, W. Leibl, A. Aukauloo, Eur. J. Inorg. Chem. 2015, 2015, 5405-5410.

[26] D.-H. Chin, G. N. La Mar, A. L. Balch, J. Am. Chem. Soc. 1980, 102 4344-4350.

[27] N. Kitajima, M. Ito, H. Fukui, Y. Moro-oka, J. Chem. Soc. Chem. Com. 1991, 0, 102-104.

[28] H. Jaafar, B. Vileno, A. Thibon, D. Mandon, Dalton Trans 2011, 40 92-106.

[29] W. A. Pryor, Ed. , Organic Free Radicals, Am. Chem. Soc. WASHINGTON, D. C., 1978.

[30] A. Vaidyalingam, P. K. Dutta, Anal. Chem. 2000, 72, 5219-5224

[31] C. Stradowski, J. Appl. Polym. Sci. 1990, 41, 2511-2512.

[32] R. N. F. Thorneley, Biochim. Biophys. Acta BBA - Bioenerg. 1974, 333, 487-496.

[33] L. Schneider, Y. Mekmouche, P. Rousselot-Pailley, A. J. Simaan, V. Robert, M. Réglier, A. Aukauloo, T. Tron, ChemSusChem 2015, 8 , 3048-3051.

[34] A. M. Dean, J. W. Bozzelli, J. Phys. Chem. 1993, 97, 4427-4441.

[35] D.-H. Chin, J. D. Gaudio, G. N. La Mar, A. L. Balch, J. Am. Chem. Soc 1977, 99, 5486-5488.

Y. Pellegrin, F. Odobel, C. R. Chim. 2017, 20, 283-295

[37] M. Heyrovský, J. Chem. Soc. Chem. Com. 1987, 1856-1857.

D. T. Sawyer, J. S. Valentine, Acc. Chem. Res. 1981, 14, 393-400.

Y. Nosaka, A. Y. Nosaka, Chem. Rev. 2017, 117, 11302-11336.

S. Hong, Y.-M. Lee, W. Shin, S. Fukuzumi, W. Nam, J. Am. Chem. Soc. 2009, 131, 13910-13911.

[41] W. Nam, Acc. Chem. Res. 2015, 48, 2415-2423.

J.-J. Girerd, F. Banse, A. J. Simaan, Struc Bond 2000, 97, 145-177.

J.-J. Girerd, F. Banse, A. J. Simaan, Struc Bond 2000, 97, 145-17
K. Chen, L. Que, Angew. Chem. Int. Ed. 1999, 38, 2227-2229.

[44] W. N. Oloo, A. J. Fielding, L. Que, J. Am. Chem. Soc. 2013, 135 6438-6441.

[45] I. Gamba, Z. Codolà, J. Lloret-Fillol, M. Costas, Coord. Chem. Rev. 2017, 334, 2-24.

[46] W. N. Oloo, L. Que, Acc. Chem. Res. 2015, 48, 2612-2621.

[47] M. Puri, A. Company, G. Sabenya, M. Costas, L. Que, Inorg. Chem. 2016, 55, 5818-5827.

[48] Y. Feng, J. England, L. Que, ACS Catal. 2011, 1, 1035-1042. 


\section{Entry for the Table of Contents}

\section{COMMUNICATION}

We found that the use of a reversible electron acceptor (methylviologen) ousts the "evil necessity" of sacrificial electron donors (SED) in the photoactivation of $\mathrm{O}_{2}$. It intervenes as an electron carrier from the excited photosensitizer to reduce both $\mathrm{O}_{2}$ and an iron(III) catalyst to form a reactive $\mathrm{Fe}^{\text {III-}}$-peroxo species for oxygen atom transfer reactions. Oxidation of an organic substrate closes the photocatalytic cycle.

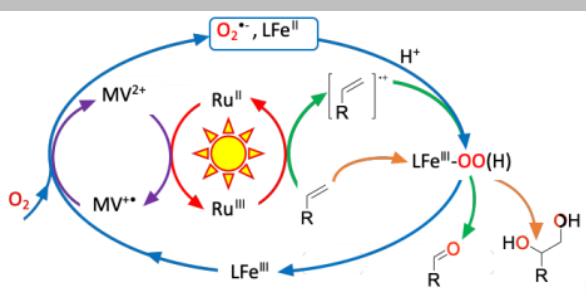

Nhat Tam Vo, ${ }^{a}$ Yasmina Mekmouche, ${ }^{b}$ Thierry Tron, ${ }^{b}$ Régis Guillot, $^{a}$ Frédéric Banse, ${ }^{a}$ Zakaria Halime, ${ }^{a}$ Marie Sircoglou, ${ }^{a}$ Winfried Leibl, ${ }^{* c}$ and Ally Aukauloo ${ }^{*} a, c$

Page No. - Page No.

Reversible Electron Relay to Exclude Sacrificial Electron Donor in Photocatalytic Oxygen Atom Transfer Reaction with $\mathrm{O}_{2}$ in Water 